\title{
Micronutrients in pregnancy
}

\author{
Robert E. Black \\ Department of International Health, Johns Hopkins School of Public Health, 615 N. Wolfe St., Baltimore, MD 21205, USA
}

\begin{abstract}
Vitamins and minerals, referred to collectively as micronutrients, have important influences on the health of pregnant women and the growing fetus. Iron deficiency results in anemia which may increase the risk of death from hemorrhage during delivery, but its effects on fetal development and birth outcomes is still unclear. Folic acid deficiency can lead to hematological consequences, pregnancy complications and congenital malformations, but again the association with other birth outcomes is equivocal. Zinc deficiency has been associated in some, but not all studies with complications of pregnancy and delivery, as well as with growth retardation, congenital abnormalities and retarded neurobehavioral and immunological development in the fetus. Iodine deficiency during pregnancy results in cretinism and possible fetal wastage and preterm delivery. Deficiency of other minerals such as magnesium, selenium, copper, and calcium have also been associated with complications of pregnancy, childbirth or fetal development. Deficiencies of vitamins other than folate may likewise be related to such complications; and vitamin A or $\beta$-carotene supplements in pregnancy reduced maternal mortality by $50 \%$ in a controlled trial in Nepal. Additional research is need on the prevalence of such deficiencies and their consequences and on cost-effective public health interventions for their control.
\end{abstract}

Pregnancy: Fetal growth: Vitamins: Minerals: Trace elements: Low birth weight: Micronutrients

Pregnancy is a period of increased metabolic demands, with changes in the woman's physiology and the requirements of a growing fetus (King, 2000). During this time, inadequate stores or intake of vitamins or minerals, referred to collectively as micronutrients, can have adverse effects on the mother, such as anemia, hypertension, complications of labor and even death (Ramakrishnan et al. 1999). Furthermore, the fetus can be affected, resulting in stillbirth, pre-term delivery, intrauterine growth retardation, congenital malformations, reduced immunocompetence and abnormal organ development.

The essential nature of micronutrients has been recognized through the identification of clinical conditions associated with severe deficiencies of particular vitamins or minerals, and through subsequent animal experiments. While the importance in pregnancy of a few micronutrient deficiencies, such as iodine, has been long recognized, the role of many others is only recently becoming appreciated. Gaining this understanding is complicated by the finding that micronutrient deficiencies often co-exist, and that deficiencies of specific vitamins and minerals vary by stage of life, season, year, ethnic group, economic status, place of residence within a country, and among individuals in the same community. This variability is due to consumption of diets with differing content and bioavailability of micronutrients and differing losses of and requirements for micronutrients. Further complicating the situation is that micronutrients can have either positive or negative interactions with regard to biological effects, and these interactions may not be the same for all possible consequences of deficiencies. Because of the possible occurrence of multiple micronutrient deficiencies in pregnant women in developing countries and the presence of numerous confounding factors (Ramakrishnan et al. 1999), observational studies related to micronutrients and pregnancy outcomes are not very illuminating. The best causal evidence for micronutrients and adverse outcomes of pregnancy comes from randomized controlled trials, and to date these have largely been done for individual vitamins or minerals. While these results can be very instructive, it is possible that correction of a single micronutrient deficiency, when one or more other limiting deficiencies are present, may not allow demonstration of the effects of that micronutrient. It might likewise be considered that correction of even multiple micronutrient deficiencies, but continued consumption of a diet that is inadequate in calories and protein, may not yield the best results for some outcomes, such as fetal growth. Nevertheless, it is important to review the results of trials with single micronutrients because demonstrated benefits would have important implications, even if negative studies of the type largely done to date cannot be said to show that a 
micronutrient deficiency is not present or that its correction is unimportant.

\section{Micronutrient deficiencies}

\section{Iron}

Iron deficiency, resulting in anemia, is highly prevalent in women in developing countries and increased iron requirements in pregnancy are not often met by changes in diet or absorption (Beard, 2000). Iron supplementation during pregnancy has been shown to improve iron stores and reduce anemia, (Hemminki \& Starfield, 1978; Milman et al. 1994) which might be expected in turn to reduce the risk of death from complications of pregnancy, such as hemorrhage (Allen, 1997). Observational studies indicate that anemia in pregnancy is correlated with poor birth outcomes, yet this association has also been found with high hemoglobin concentrations, suggesting a U-shaped distribution of risk (Garn et al. 1981). Iron supplementation during pregnancy has been recommended by national and international bodies (US Preventive Services Task Force, 1993), and has become the standard of care in most settings, making randomized controlled trials difficult to justify. The few such trials that have been done in developing country populations show equivocal results with regard to birth weight (Menendez et al. 1994; Preziosi et al. 1997), although one trial did find a significant reduction in fetal loss and neonatal mortality (Preziosi et al. 1997).

\section{Folic acid}

Folic acid has long been provided as a supplement in combination with iron during pregnancy, largely on the basis of hematological benefits (Fleming et al. 1986), although deficiency has also been associated with pregnancy complications and congenital malformations (Scholl \& Johnson, 2000). Particularly the recent demonstration of the causal role of folic acid deficiency in neural tube defects has brought attention to this vitamin (MRC Vitamin Study Research Group, 1991), yet this is related to periconceptional folic acid status and supplementation, after pregnancy is detected, would have little effect. The role of folic acid deficiency in other birth outcomes, such as low birth weight, pre-term delivery, and peri-natal mortality, is unclear (Scholl \& Johnson, 2000). Limited data suggest that folic acid supplementation of pregnant women in developing countries may improve fetal growth and reduce the incidence of low birth weight (Iyengar \& Rajalakshmi, 1975; Baumslag et al. 1970). These and other birth outcomes need further study.

\section{Zinc}

Zinc deficiency has been associated with complications of pregnancy and delivery, such as pre-eclampsia, premature rupture of membranes, and pre-term delivery, and with fetal growth retardation and congenital abnormalities (Caulfield et al. 1998). Randomized controlled trials of zinc supplementation have largely been done in developed countries, where zinc deficiency is infrequent. Trials that found benefits, e.g. a reduction in the incidence of pregnancy-induced hypertension or of low birth weight or pre-term delivery, often selected women who were less well nourished or had low plasma zinc concentrations (Jameson, 1982; Goldenberg et al. 1995). Thus, in developed country populations there may be benefits in particular populations. Some trials of zinc supplementation in developing countries, where zinc deficiency is likely to be common, have found significant benefits on pregnancy complications or birth outcomes (Garg et al. 1993), but others have not (Caulfield et al. 1999; Osendarp et al. 2000).

Some trials of zinc supplementation in pregnancy in developing countries have found other beneficial outcomes that need further investigation. The important role of zinc in fetal neural growth and development has been demonstrated in animal models (Caulfield et al. 1998). One trial in a developing country found that zinc-supplemented pregnant women had fetuses with indications of enhanced neurobehavioral development, compared with those of nonsupplemented women (Merialdi et al. 1998). This finding needs confirmation and the implications for child development should be assessed. In animal models, zinc deficiency at the time of conception is associated with congenital abnormalities (Jameson, 1993). Although difficult to study in humans, the potential importance of this deficiency in the etiology of birth defects suggests that trials are needed to answer the question. Zinc deficiency in utero has many adverse effects on the development of the fetal immune system (Shankar \& Prasad, 1998; Wellinghausen, in press). Trials in developing countries have found that babies whose mothers were given zinc supplements in pregnancy have improved immune function and a reduction in diarrhea and respiratory illnesses in infancy, suggesting effects on immune competence that persist beyond birth (Osendarp et al. 2000).

\section{Iodine}

Iodine has a clear link with thyroid function in pregnancy, when deficiency results in cretinism and possibly fetal wastage or pre-term delivery (Dunn, 1993). Control of this widespread problem in developing countries has focused on administration of iodized oil before or during pregnancy and on making iodized salt available in iodine-deficient settings (Hetzel, 1987).

\section{Magnesium}

Magnesium deficiency is associated with pre-eclampsia, and pre-term delivery (Chien et al. 1996), and possibly with low birth weight. Of the trials in developed country settings, some found fewer pre-term births and less intrauterine growth retardation with magnesium supplementation during pregnancy (Conradt et al. 1985; Spatling \& Spatling, 1988; Sibai et al. 1989). Unfortunately, data are not available from developing countries. 


\section{Other minerals}

Other minerals may be associated with pregnancy complications or adverse birth outcomes. Selenium and copper deficiencies may be associated with adverse outcomes of pregnancy and reduced fetal growth (Arnaud et al. 1994; Ghebremeskal et al. 1994), but need to be studied by randomized controlled trials, especially in developing countries where deficiencies are more common. Deficiency of calcium, may also be associated with abnormal fetal development, pregnancy induced hypertension, and preterm delivery (Ritchie \& King, 2000; Villar \& Belizen, 2000).

\section{Vitamins}

Deficiencies of vitamins other than folate may also be related to complications of pregnancy and abnormal fetal development. Vitamin A deficiency during gestation can lead to fetal wastage, although high doses of vitamin A in early pregnancy can be teratogenic as well (Azais-Braesco $\&$ Pasca, 2000). The striking finding that weekly vitamin A or $\beta$-carotene supplements reduced maternal mortality by $50 \%$ in a controlled trial in Nepal (West et al. 1999) has led to plans to replicate these findings in trials with vitamin A or combinations of micronutrients. Thiamine, vitamin B6 and B12 deficiencies are of unknown importance for pregnancy outcomes, but associations have been made with fetal development (Ramakrishnan et al. 1999). A recent controlled trial in HIV-infected women using high-dose B vitamins, as well as vitamins $\mathrm{C}$ and $\mathrm{E}$, found reductions in intrauterine growth retardation and pre-term births, as well as a reduction in perinatal mortality (Fawzi et al. 1998). Vitamin $\mathrm{C}$ and $\mathrm{E}$ deficiencies have been associated with complications of pregnancy, but randomized trials are needed to determine the true relationships (Ramakrishnan et al. 1999). One such recent trial found that provision of vitamins $\mathrm{C}$ and $\mathrm{E}$ resulted in a $60 \%$ lower rate of preeclampsia (Chappell et al. 1999).

\section{Micronutrient interactions}

Micronutrient interactions are numerous and there may be benefits to correcting two or more simultaneous deficiencies. For example, vitamin A contributes to anemia by interfering with iron utilization; provision of both vitamin $A$ and iron has been shown to have a greater effect on anemia than iron alone (Suharno et al. 1993). In another study, the addition of both vitamin $\mathrm{A}$ and zinc to iron therapy had more effect on anemia than iron alone (Kolsteren et al. 1999). A further example is that vitamin C can increase the absorption of iron (Skikne \& Baynes, 1994). On the other hand, some micronutrients could have adverse effects on others, e.g. iron supplements can interfere with the absorption of zinc (Hambidge et al. 1987; Solomons \& Ruz, 1997) and zinc in high doses, with absorption of iron or copper (Solomons \& Ruz, 1997; Festa et al. 1985; Porter et al. 1977). To date there is little evidence of negative interactions in humans with physiological doses of micronutrients, e.g. about one recommended daily allowance, in supplements, particularly if they are given with food. Because of the potential to achieve greater benefits with combined, rather than single, micronutrients, as well as the need to address unanswered questions about safety, there is an urgent need to evaluate these interactions in populations potentially deficient in one or more of the micronutrients.

Considerations, that there may be multiple deficiencies in developing countries and that it is difficult to evaluate the effects of all of the potentially important micronutrients, as well as their possible interactions, have led some to conclude that a multivitamin-mineral supplement should be given during pregnancy (UNICEF, 1999). While this has become common practice in developed countries, the empirical evidence for benefit on pregnancy outcomes is limited. Observational studies suggest that consumption of micronutrient supplements in pregnancy is associated with higher birth weight and other outcomes; however, these studies are likely to be confounded and biased. The very few randomized controlled trials available from developed countries have found limited benefits on pregnancy outcomes and have not been designed to show if multiple micronutrients are better than single micronutrients, such as folic acid or zinc (Czeizel, 1993). It should also be considered that a combination of micronutrients could have less effect than more selective supplementation. The potential for negative interactions and adverse effects with multiple micronutrient supplementation needs evaluation (Ladipo, 2000). Some studies are now underway in developing countries to address these questions.

\section{Conclusions}

Micronutrient adequacy at the time of conception and during gestation is clearly important for a number of pregnancy outcomes. The need for specific micronutrients, such as folic acid and possibly zinc, at the time of conception to prevent birth defects poses a challenge since an effective intervention would need to improve the status of all reproductive age women, or at least those at high risk of conception. For other outcomes, intervention after pregnancy is detected may be effective. The usual approach to improve micronutrient status during pregnancy, i.e. for iron and folic acid, is supplementation. This approach has been problematic due to limited supplies, inadequate training of health workers, and poor adherence to the supplementation schedule with suboptimal effects on anemia (ACC/SCN, 1992). While the addition of other micronutrients to such supplements would have low marginal cost, it would not necessarily improve adherence to therapy and may even worsen it. Additional research is needed on the possible beneficial and harmful effects of multiple or more selective micronutrient supplements in pregnancy before universal recommendations can be made for developing country populations. In addition, more attention should be focused on dietary approaches, including fortification of foods with micronutrients, which may prove to be more beneficial and sustainable than provision of supplements during pregnancy. Such approaches would encompass increasing energy and macronutrient intakes, as well as micronutrient intakes, which may be more advantageous in improving birth 
weight and length of gestation than micronutrient supplements alone.

\section{References}

ACC/SCN (1992) Second Report on the World Nutrition Situation. Global and Regional Results, volume 1, ACC/SCN, Geneva.

Allen LH (1997) Pregnancy and iron deficiency: unresolved issues. Nutrition Reviews 55, 91-101.

Arnaud J, Preziosi L, Mashako L, Galan P, Favier A, Kapongo C \& Hercberg S (1994) Serum trace elements in Zairian mothers and their newborns. European Journal of Clinical Nutrition 48, 341-348.

Azais-Braesco V \& Pasca G (2000) Vitamin A in pregnancy: requirements and safety limits. American Journal of Clinical Nutrition 71 (suppl.), 1325-1333.

Baumslag N, Edelstein T \& Metz J (1970) Reduction of incidence of prematurity by folic acid supplementation in pregnancy. British Medical Journal 1, 16-17.

Beard JL (2000) Effectiveness and strategies of iron supplementation during pregnancy. American Journal of Clinical Nutrition 71 (suppl.), 1288-1294.

Caulfield LE, Zavaleta N, Shankar AH \& Merialdi M (1998) Potential contribution of maternal zinc supplementation during pregnancy to maternal and child survival. American Journal of Clinical Nutrition 68 (suppl.), 499-508.

Caulfield LE, Zavaleta N, Figueroa A \& Leon Z (1999) Maternal zinc supplementation does not affect size at birth or pregnancy duration in Peru. Journal of Nutrition 129, 1563-1568.

Chappell LC, Seed PT, Briley AL, Kelly FJ, Lee R, Hunt BJ, Pamar K, Bewley SJ, Shennan AH, Steer PH \& Poston L (1999) Effect of antioxidants on the occurrence of pre-eclampsia in women at increased risk: a randomized trial. Lancet 354, 810816.

Chien PFW, Khan KS \& Arnott N (1996) Magnesium sulphate in the treatment of eclampsia and pre-eclampsia: an overview of the evidence from randomized trials. British Journal of Obstetrics and Gynecology 103, 1085-1091.

Conradt A, Weidinger H \& Algayer H (1985) Magnesium therapy decreased the rate of intrauterine fetal retardation, premature rupture of membranes and premature delivery in risk pregnancies treated with betamimetics. Magnesium 4, 20-28.

Czeizel AE (1993) Controlled studies of multivitamin supplementation on pregnancy outcomes. Annals of New York Academy of Sciences 687, 266-275.

Dunn JT (1993) Iodine supplementation and the prevention of cretinism. Annals of New York Academy of Sciences 678, 158168.

Fawzi WW, Msamanga GI, Spiegelman D, Urassa EJN, McGrath N, Mwakagile D, Antelman G, Mbise R, Herrera G, Kapiga S, Willett W \& Hunter DJ for the Tanzania Vitamin and HIV Infection Trial Team (1998) Randomised trial of effects of vitamin supplements on pregnancy outcomes and T cell counts in HIV-1-infected women in Tanzania. Lancet 351, 1477-1482.

Festa MD, Anderson HL, Dowdy RP \& Ellersieck MR (1985) Effect of zinc intake on copper excretion and retention in men. American Journal of Clinical Nutrition 41, 258-292.

Fleming AF, Ghatoura GBS, Harrison KA, Briggs ND \& Dunn DT (1986) The prevention of anaemia in pregnancy in primigravidar in the Guinea savanna of Nigeria. Annals of Tropical Medicine and Parasitology 80, 211-233.

Garg HK, Singhal KC \& Arshad Z (1993) A study of the effects of oral zinc supplementation during pregnancy outcomes. Indian Journal of Physiology and Pharmacology 37, 276-284.

Garn SM, Ridella SA, Petzold S \& Falkner F (1981) Maternal Hb levels and pregnancy outcomes. Seminars in Perinatology 5, $155-162$.

Ghebremeskal K, Burns L, Burden TJ, Harbige L, Costeloe K, Powell JJ \& Crawford M (1994) Vitamin A and related essential nutrient in cord blood: relationships with anthropometric measurements at birth. Early Human Development 39, $177-188$.

Goldenberg RL, Tamura T, Neggers Y, Copper RL, Johnston K, Dubard MG \& Hauth JC (1995) The effect of zinc supplementation on pregnancy outcome. Journal of American Medical Association 274, 463-468.

Hambidge KM, Krebs NF, Sibley L \& English J (1987) Acute effects of iron therapy on zinc status during pregnancy. Obstetrics and Gynecology 70, 593-596.

Hemminki E \& Starfield B (1978) Routine administration of iron and vitamins during pregnancy: review of controlled clinical trials. British Journal of Obstetrics and Gynecology 85, 404410.

Hetzel BS (1987) An overview of the prevention and control of iodine deficiency disorders. In The Prevention and Control of Iodine Deficiency Disorders, 7, pp. 31-34 [BS Hetzel, JT Dunn and JB Stanbury, editors]. Amsterdam: Elsevier.

Iyengar L \& Rajalakshmi K (1975) Effect of folic acid supplementation on birth weights of infants. American Journal of Obstetrics and Gynecology 122, 332-336.

Jameson S (1982) Zinc status and pregnancy outcome in humans. In Clinical Applications of Recent Advances in Zinc Metabolism, pp. 39-52 [AS Prasad, IE Dreosti and BS Hetzel, editors]. New York: Alan R. Liss..

Jameson S (1993) Zinc status in pregnancy: the effect of zinc therapy on perinatal mortality, prematurity, and placental ablation. Annals of New York Academy of Sciences 678, 178192.

King JC (2000) Physiology of pregnancy and nutrient metabolism. American Journal of Clinical Nutrition 71 (suppl.), 1218-1225.

Kolsteren P, Rahman SR, Kilderbrand K \& Diniz A (1999) Treatment for iron deficiency anaemia with a combined supplementation of iron, vitamin A and zinc in women of Dinajpur, Bangladesh. European Journal of Clinical Nutrition 53, 102-106.

Ladipo OA (2000) Nutrition in pregnancy: mineral and vitamin supplements. American Journal of Clinical Nutrition 72 (S), 280-290.

Menendez C, Todd J, Alonso PL, Francis N, Lulat S, Ceesay S \& Boge BM (1994) The effects of iron supplementation during pregnancy, given by traditional birth attendants, on the prevalence of anaemia and malaria. Transactions of the Royal Society of Tropical Medicine and Hygiene 88, 590-593.

Merialdi M, Caulfield LE, Zavaleta N, Figueroa A \& DiPietro JA (1998) Adding zinc to prenatal iron and folate tablets improves fetal neurobehavioral development. American Journal of Obstetrics and Gynecology 180, 483-490.

Milman N, Agger AO \& Nielsen OJ (1994) Iron status markers and serum erythropoietin in 120 mothers and newborn infants: effect of iron supplementation in normal pregnancy. Acta Obstetrics and Gynecology Scan 73, 200-204.

MRC Vitamin Study Research Group (1991) Prevention of neural tube defects: results of Medical Research Council Vitamin Study. Lancet 338, 131-137.

Osendarp SJM, van Raaij JMA, Arifeen SE, Wahed MA, Baqui AH \& Fuchs GJ (2000) A randomized, placebocontrolled trial of the effect of zinc supplementation during pregnancy on pregnancy outcomes in Bangladeshi urban poor. American Journal of Clinical Nutrition 71, 114-119.

Porter KG, Mcmaster D, Elmes ME \& Love AHG (1977) Anaemia and low serum-copper during zinc therapy. Lancet ii, 774. 
Preziosi P, Prual A, Galan P, Daouda H, Boureima H \& Hercberg S (1997) Effect of iron supplementation on the iron status of pregnant women: consequences for newborns. American Journal of Clinical Nutrition 66, 1178-1182.

Ramakrishnan U, Manjrekar R, Rivera J, Gonzales-Cossio T \& Martorell R (1999) Micronutrients and pregnancy outcome: a review of the literature. Nutrition Research 19, 103-159.

Ritchie LD \& King JC (2000) Dietary calcium and pregnancyinduced hypertension: is there a relation. American Journal of Clinical Nutrition 71 (suppl.), 1371-1374.

Scholl TO \& Johnson WG (2000) Folic acid: influence on the outcome of pregnancy. American Journal of Clinical Nutrition 71, 1295-1303.

Shankar AH \& Prasad A (1998) Zinc and immune function: the biological basis of altered resistance to infection. American Journal of Clinical Nutrition 68 (Suppl.), 447-463.

Sibai BM, Villar L \& Bray E (1989) Magnesium supplementation during pregnancy. A double-blind randomized controlled clinical trial. American Journal of Obstetrics and Gynecology 161, 115-119.

Skikne B \& Baynes RD (1994) Iron absorption. In Iron Metabolism in Health and Disease, pp. 151-187 [JH Brock, JW Halliday, MJ Pippard and LS Powell, editors]. London: WB Saunders.

Solomons NW \& Ruz M (1997) Zinc and iron interaction: concepts and perspectives in the developing world. Nutrition Research 17, 177-185.

Spatling L \& Spatling G (1988) Magnesium supplementation in pregnancy: a double blind study. British Journal of Obstetrics and Gynecology 95, 120-125.

Suharno D, West CE, Muhilal , Karyadi D \& Hautvast JGAJ (1993) Supplementation with vitamin A and iron for nutritional anaemia in pregnant women in west Java, Indonesia. Lancet 342, 1325-1328.

UNICEF (1999) Composition of a multi-micronutrient supplement to be used in pilot programmes among pregnant women in developing countries.

US Preventive Services Task Force (1993) Routine iron supplementation during pregnancy. Policy statement. Journal of the American Medical Association 2702846-2848

Villar J \& Belizen JM (2000) Same nutrient, different hypotheses: disparities in trials of calcium supplementation during pregnancy. American Journal of Clinical Nutrition 71 (suppl.), $1375-1379$.

West KP Jr, Katz J, Khatry SK, LeClerq SC, Pradhan EK, Shrestha SR, Connor PB, Dali SM, Christian P, Pokhrel RP \& Sommer A the NNIPS-2 Study Group (1999) Double blind, cluster randomized trial of low dose supplementation with vitamin $A$ or $\beta$-carotene on mortality related to pregnancy in Nepal. British Medical Journal 318, 570-575. 